Correction

Correction: Twardowski, M.; Tonizzo, A. Ocean Color Analytical Model Explicitly Dependent on the Volume Scattering Function. Applied Sciences 2018, 8,2684

Michael Twardowski ${ }^{1,2, *}$ and Alberto Tonizzo ${ }^{2, *}$

1 Harbor Branch Oceanographic Institute, Florida Atlantic University, Ft. Pierce, FL 34946, USA

2 Sunstone Scientific LLC, Vero Beach, FL 32963, USA

* Correspondence: mtwardowski@fau.edu (M.T.); alberto.tonizzo@gmail.com (A.T.)

Received: 20 June 2018; Accepted: 23 January 2019; Published: 6 March 2019

check for updates

We, the authors, wish to make the following corrections to our paper [1]. On page six, immediately after Equation (6), $\psi_{K L u}$ should be replaced with $\Psi_{K_{L u}}$. These changes have no material impact on the conclusions of our paper.

The authors would like to apologize for any inconvenience caused. The change does not affect the scientific results.

\title{
Change in Figures/Tables
}

The authors wish to make the following correction to this paper. Due to mislabeling, replace Figure 1:

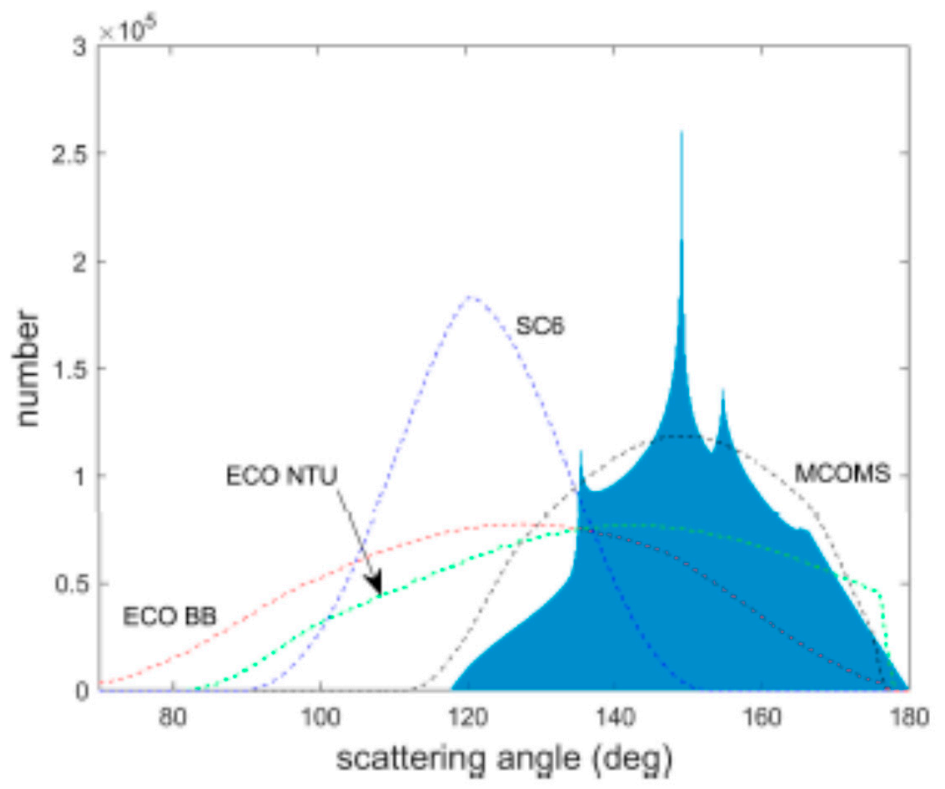

with this high-resolution figure: 


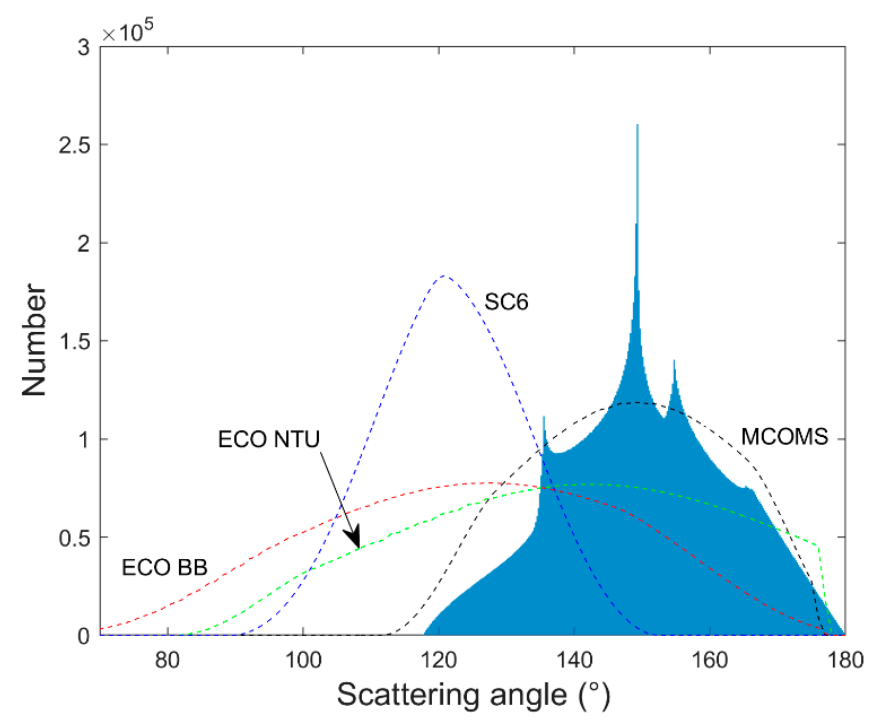

Also, due to mislabeling, replace Figure 3:
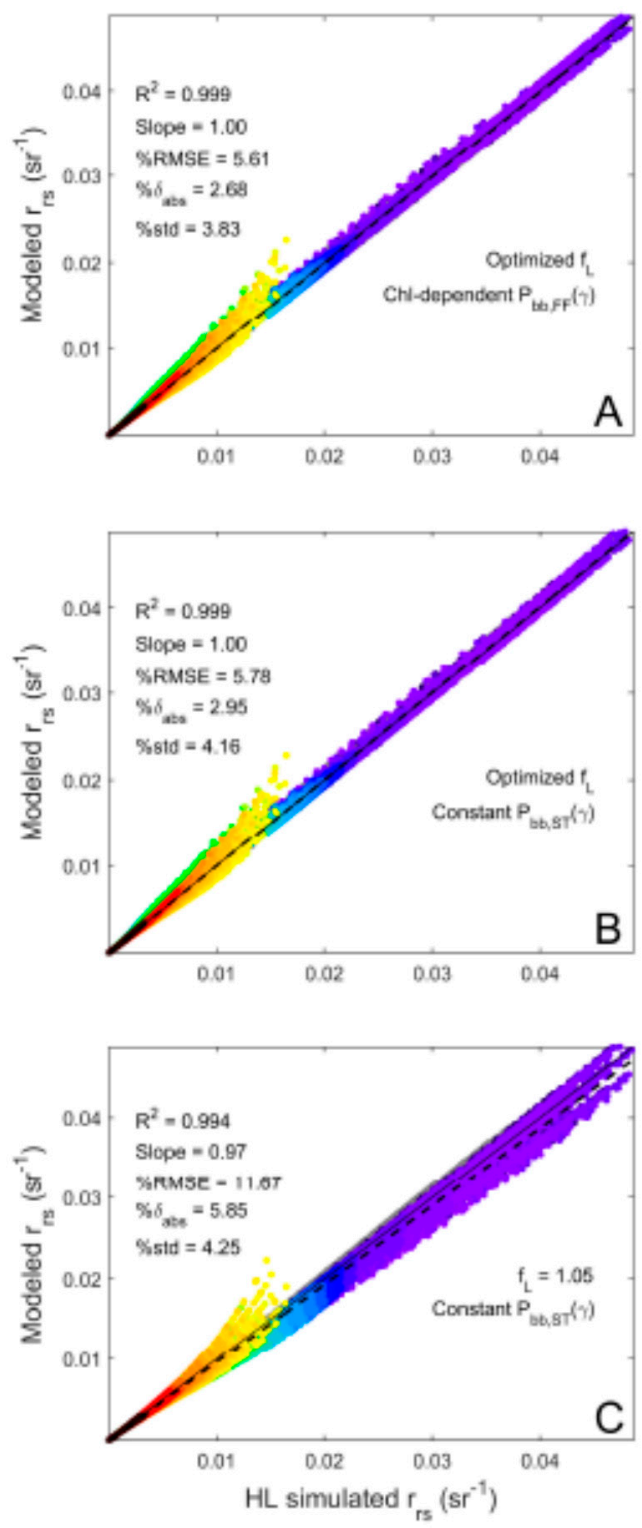
with this high-resolution figure:
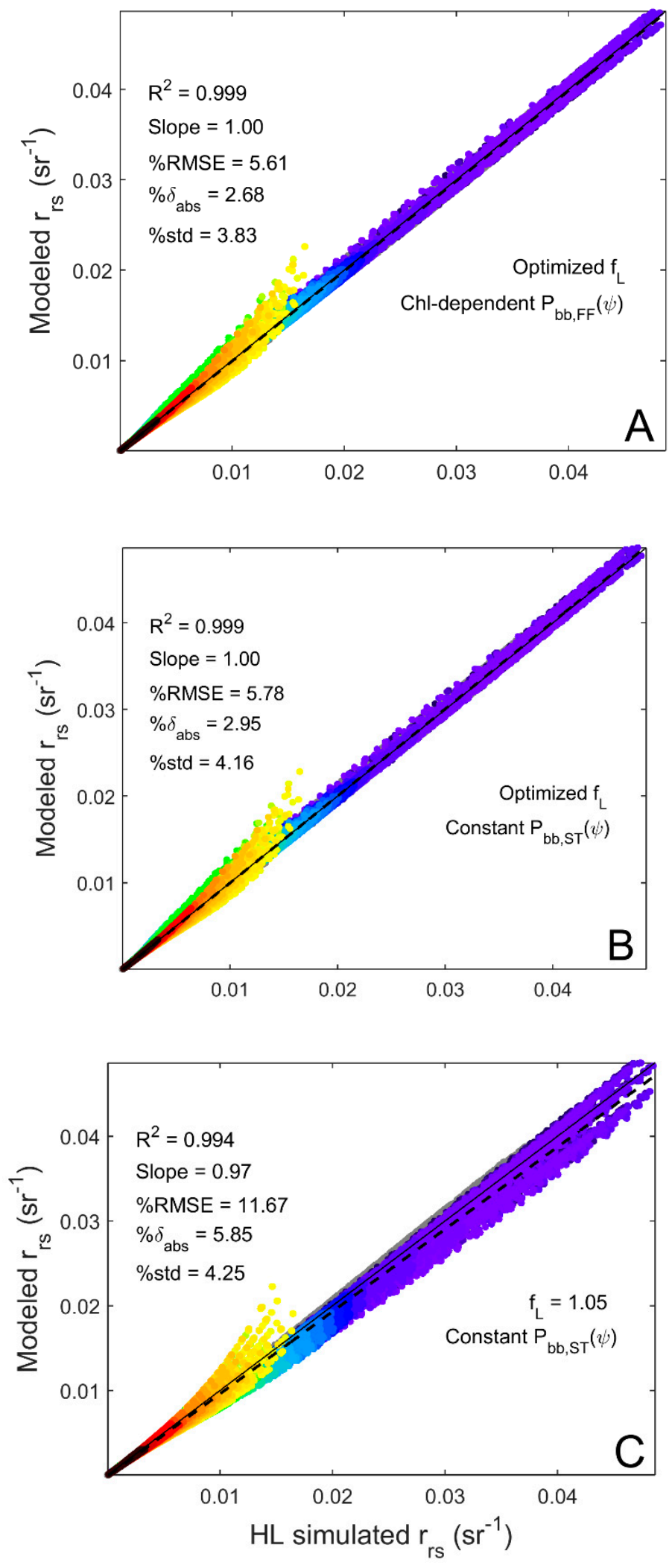


\section{Reference}

1. Twardowski, M.; Tonizzo, A. Ocean Color Analytical Model Explicitly Dependent on the Volume Scattering Function. Appl. Sci. 2018, 8, 2684. [CrossRef] 